\title{
Atividade fotossintética e produtividade de alface cultivada sob sombreamento ${ }^{1}$
}

\author{
Antonia Mirian Nogueira de Moura Guerra ${ }^{2}$; Ana Cecília Moura Costa ${ }^{3}$; Paula Raniele de Freitas \\ Tavares $^{3}$
}

\author{
${ }^{1}$ Submetido em: 18-06-2016 e aprovado em: 30-06-2017 \\ ${ }^{2}$ Prof $^{\mathrm{a}}$. Dr ${ }^{\mathrm{a}}$. da Universidade Federal do Oeste da Bahia campus Barra (UFOB), Barra - BA, CEP: 47.100-000; \\ email: mirianagronoma@hotmail.com \\ ${ }^{3}$ Acadêmicas do curso de Agronomia do Instituto de Biodiversidade e Florestas (IBEF) da Universidade Federal \\ do Oeste do Pará (UFOPA), Santarém - PA, CEP: 68.035-110; email: ceciprinces@gmail.com
}

\begin{abstract}
Resumo - Um experimento foi conduzido para avaliar o efeito de telas de sombreamento em relação ao pleno sol sobre a capacidade fotossintética e a produtividade de alface crespa cultivar Elba nas condições climáticas de Santarém - PA. O delineamento experimental utilizado foi blocos casualizados completos com quatro repetições. Foram estudados dois tipos de tela de sombreamento e um plástico(tela verde de $50 \%$, tela preta de $50 \%$ e plástico transparente de $150 \mu \mathrm{m}$ ) além da testemunha (cultivo a pleno sol). Foram avaliados a altura, diâmetro, número de folhas e peso de uma planta, produtividade, razão de massa de folha (RMF) e de caule (RMC), além da taxa de assimilação líquida de carbono $(A)$, condutância estomática ao vapor de água $\left(g_{s}\right)$, taxa transpiratória $(E)$, eficiência instantânea no uso da água $(A / E)$ e relação entre as concentrações interna e externa de carbono $\left(C_{i} / C_{a}\right)$. A tela verde e o plástico proporcionaram ganho de produtividade $(49,26 \%$ e $48,47 \%$, respectivamente, em relação ao cultivo a pleno sol) em virtude do maior número de folhas, peso de uma planta e alocação de massa seca para as folhas. A taxa fotossintética e a eficiência no uso da água tiveram aumentos de $24,1 \%$ e $21,94 \%$, respectivamente, com o uso do plástico em relação à condução em pleno sol. Sob o plástico transparente, ocorreram maior condutância estomática, concentração de $\mathrm{CO}_{2}$, taxa fotossintética, melhor eficiência no uso da água e maior acúmulo de massa seca. Os aumentos de produtividade para alface cultivado sob as telas de sombreamento se deram através de incrementos na atividade fotossintética das plantas.
\end{abstract}

Palavras-chave: Condutância estomática; Fotossíntese; Massa seca; Radiação.

\section{Photosynthetic activity and yield of lettuce grown under shading}

\begin{abstract}
An experiment was conducted to evaluate the effect of shading screens in relation to the full sun on the photosynthetic capacity and productivity of Elbe crested lettuce in the climatic conditions of Santarém - PA. The experimental design was completely randomized blocks with four replicates. Two types of shading and one plastic (50\% green screen, $50 \%$ black screen and $150 \mu \mathrm{m}$ transparent plastic) were studied in addition to the control (full sun). The height, diameter, number of leaves and weight of a plant, yield, leaf mass ratio (RMF) and stem ratio (RMC) were evaluated, as well as the net carbon assimilation rate $(A)$, stomatal conductance to steam Water $\left(g_{s}\right)$, transpiration rate $(E)$, instantaneous water use efficiency $(A / E)$ and relation between internal and external carbon concentrations $\left(C_{i} / C_{a}\right)$. The green screen and the plastic provided a productivity gain $(49.26 \%$ and $48.47 \%$, respectively, in relation to the cultivation in full sun) due to the greater number of leaves, weight of a plant and allocation of dry mass to the sheets. The photosynthetic rate and the water use efficiency increased $24.1 \%$ and $21.94 \%$, respectively, with the use of plastic in relation to the conduction in full sun. Under the transparent plastic, greater stomatal conductance, $\mathrm{CO}_{2}$ concentration, photosynthetic rate, better water use efficiency and greater dry mass accumulation occurred. The yield increases for lettuce grown under the shade screens were due to increases in the photosynthetic activity of the plants.
\end{abstract}

Keyword: Stomatal conductance; Photosynthesis; Dry mass; Radiation. 


\section{Introdução}

A alface (Lactuca sativa L.) é a hortaliça folhosa mais consumida no Brasil e no mundo, sendo apreciada em saladas e sanduíches, além de ser uma fonte de vitaminas e minerais. A frágil constituição de suas folhas a torna propensa a ferimentos, desidratação, injúrias mecânicas, ataque por insetos e patógenos e queimaduras pelo excesso de radiação, demandando, portanto, maior cuidado ao longo da produção.

A alface é uma planta que se adapta às condições de menor fluxo de energia radiante, pelo fato da intensidade luminosa afetar diretamente o seu crescimento e desenvolvimento. Quando se conduz uma cultura dentro de uma variação ótima de luminosidade com outros fatores favoráveis, a fotossíntese é elevada, a respiração é normal e a quantidade de matéria seca acumulada é alta. Esses benefícios à cultura podem ser viabilizados com o uso de tela de polipropileno que reduz a incidência direta dos raios solares (BEZERRA NETO et al., 2005a).

As telas de sombreamento no interior do ambiente protegido podem proporcionar condição microclimática apropriada para $\mathrm{o}$ desenvolvimento da cultura, reduzindo os efeitos nocivos da alta taxa de incidência da radiação solar e da temperatura sobre a planta (SHAHAK et al., 2004).

Além das telas de sombreamento de cor preta, novas tecnologias na utilização de telas estão sendo empregadas com o objetivo principal de proteger as plantas da radiação. Esses materiais de polietileno de baixa densidade (PEBD) são de várias colorações (azul, vermelho, amarelo, cinza) com funções específicas na sua utilização. Por exemplo, a malha termo-refletora de alumínio, que promove boa ventilação, distribuição uniforme da luz e aporte máximo da luz difusa e da reflexão da radiação infravermelha, tanto para evitar o excesso da temperatura como para economizar energia (HUERTAS, 2006). As telas de coloração vermelha transferem mais a luz do espectro nas ondas vermelho e vermelho distante e difundem a luz que passa através da malha, sendo eficiente no desenvolvimento da planta; já as telas de coloração azul proporcionam luz do espectro em comprimento de onda de 440-490 nm, intensificando o fototropismo e a fotossíntese (LI, 2006).
Pereira et al. (2011) observaram que o cultivo de melões sob Aluminet ${ }^{\circledR} \quad 30 \%$ proporcionou melhor desempenho em crescimento e produção do meloeiro, indicando que esta não é uma cultura altamente exigente em luz, e que cultivo sob restrição de luz mostrou-se promissor abrindo perspectivas para o cultivo em sistemas agroflorestais, associados ou em ambiente protegido.

Costa et al. (2011a) constataram que sob sombreamento houve aumento na produção total e na massa fresca dos frutos de morango, sendo que os incrementos na radiação fotossinteticamente ativa colaboraram para maiores taxas fotossintéticas e a temperatura constante no interior do ambiente favoreceu a concentração do florescimento.

As alterações no metabolismo induzidas pela intensidade luminosa são resultado de várias respostas fisiológicas da planta, dentre as quais se destacam as modificações no crescimento, na transpiração, no comportamento estomático, atividade fotossintética e por fim, acúmulo de massa seca.

Dentre os trabalhos relacionados com a atividade fotossintética e condutância estomática em alface, podemos citar aqueles relacionados a diferentes intensidades luminosas (KIM et al., 2004) e respostas à variação de temperatura (HE; TAN; LEE, 2009). Portanto, a busca de mais informações sobre a fisiologia dos órgãos fotossintetizantes da cultura da alface em ambiente protegido é de fundamental importância. Dessa forma, neste trabalho objetivou-se avaliar o efeito de telas de sombreamento e plástico transparente sobre a atividade fotossintética e a produtividade de alface nas condições de Santarém-PA.

\section{Material e Métodos}

$\mathrm{O}$ experimento foi conduzido em área comercial de um horticultor na comunidade rural do Tabocal, município de Santarém - PA $\left(02^{\circ} 24^{\prime}\right.$ $52^{\prime \prime} \mathrm{S} ; 54^{\circ} 42^{\prime} 36^{\prime \prime} \mathrm{W} ; 152 \mathrm{~m}$ de altitude) na mesorregião do Baixo Amazonas. O clima da região segundo a classificação de Köppen, é do tipo Ami, tropical com uma estação anual seca de dois a três meses e precipitação anual média de 2.000 mm (SILVA; NECHET, 2006). Utilizou-se a cultivar de alface crespa Elba (Empresa TopSeed). As mudas foram produzidas sob ambiente protegido, em bandejas de poliestireno 
de 128 células, preenchidas com substrato agrícola comercial (PlantMax ${ }^{\circledR}$ ) e transplantadas 28 dias após a semeadura, com 4 folhas definitivas.

A análise do solo da área experimental (0$20 \mathrm{~cm}$ ) apresentou as características: $\mathrm{pH} \mathrm{em} \mathrm{H}_{2} \mathrm{O}$ $=6,7 ; \mathrm{P}=8,9 \mathrm{mg} \mathrm{dm}^{-3}$ (Mehlich 1); $\mathrm{K}=94 \mathrm{mg}$ $\mathrm{dm}^{-3} ; \mathrm{Ca}^{2+}=4,6 \mathrm{cmol}_{\mathrm{c}} \mathrm{dm}^{-3} ; \mathrm{Mg}^{2+}=1,3 \mathrm{cmol}_{\mathrm{c}} \mathrm{dm}^{-}$ 3; $\mathrm{H}+\mathrm{Al}=1,9 \mathrm{cmol}_{\mathrm{c}} \mathrm{dm}^{-3}, \mathrm{~S}=6,1 \mathrm{cmol}_{\mathrm{c}} \mathrm{dm}^{-3}, \mathrm{~V}$ $=76 \%$ e $\mathrm{M} \cdot \mathrm{O}=28,7 \mathrm{~g} \mathrm{~kg}^{-1}$.

O solo foi preparado por meio de uma aração, uma gradagem, levantamento dos canteiros e abertura manual dos sulcos de plantio com auxílio de enxadas. A fertilização da cultura foi realizada com base na análise química do solo e recomendações para a cultura no estado de Minas Gerais (RIBEIRO; GUIMARÃES; ALVAREZ, 1999). Na adubação de plantio os nutrientes foram distribuídos e incorporados cinco dias antes do transplante das mudas, sendo aplicados $300 \mathrm{~kg} \mathrm{ha}^{-1}$ de $\mathrm{P}_{2} \mathrm{O}_{5} ; 30 \mathrm{~kg} \mathrm{ha}^{-1}$ de $\mathrm{K}_{2} \mathrm{O}$ e $30 \mathrm{~kg} \mathrm{ha}^{-1} \mathrm{de} \mathrm{N}$, tendo como fontes superfosfato simples, cloreto de potássio e sulfato de amônio, respectivamente. Aplicaram-se ainda, no plantio, $15 \mathrm{~kg} \mathrm{ha}^{-1}$ de sulfato de zinco, $10 \mathrm{~kg} \mathrm{ha}^{-1}$ de bórax, $10 \mathrm{~kg} \mathrm{ha}^{-1}$ de sulfato de cobre e $0,5 \mathrm{~kg} \mathrm{ha}^{-1}$ de molibdato de amônio. Uma adubação de cobertura com $\mathrm{N}$ e $\mathrm{K}$ foi realizada aos 14 dias após o transplante (DAT) das mudas, sendo aplicados $30 \mathrm{~kg} \mathrm{ha}^{-1}$ de $\mathrm{N}$ e $30 \mathrm{~kg} \mathrm{ha}^{-1}$ de $\mathrm{K}_{2} \mathrm{O}$, nas forma de uréia e cloreto de potássio, respectivamente.

Utilizou-se o delineamento em blocos inteiramente casualizado, com quatro repetições. As parcelas foram constituídas de quatro ambientes (pleno sol; tela de sombreamento preta de $50 \%$; tela de sombreamento verde de $50 \%$; e plástico transparente de $150 \mu \mathrm{m})$. As telas foram instaladas em estruturas tipo "telado" totalmente aberto nas dimensões de $1,5 \times 4,0 \times 12,0 \mathrm{~m}$ (altura, largura e comprimento). Cada unidade experimental constituiu-se de quatro canteiros, sendo os dois centrais com quatro linhas e os dois da periferia com duas linhas cada, com plantas espaçadas de 0,25 x 0,25 m. Foram consideradas úteis as duas fileiras centrais dos canteiros intermediários, excetuando-se duas plantas de cada extremidade.

Durante a condução do experimento foram realizadas duas capinas manuais conforme necessidade da cultura. A irrigação foi realizada por microaspersão e o manejo desta por meio de coeficientes de cultura e evaporação dos tanques classe A (instalado em estação meteoróloga da universidade). Foi realizada uma pulverização com calda de alho e pimenta do reino para controle da mosca branca (Bemisia sp.).

Na colheita, aos 35 dias após o transplante (DAT), foram colhidas, dentre as plantas úteis, 10 por repetição. A parte aérea dessas foi submetida à lavagem, e foram avaliados: altura da planta; diâmetro da cabeça; número de folhas por planta; massa fresca de uma planta; produtividade; produção de massa seca de parte aérea (caule + folhas) e razão de massa de folhas (RMF - razão entre a massa seca das folhas e a massa seca total) e de caule (RMC - razão entre a massa seca do caule e a massa seca total). A massa seca foi obtida pela pesagem após secagem em estufa com circulação de ar a $70{ }^{\circ} \mathrm{C}$ até massa constante.

As trocas gasosas foram avaliadas aos 30 dias após o transplantio entre as 9:00 e 11:00h da manhã, tomado-se as leituras na folha completamente expandida localizada na parte intermediária da planta. Para tal foi utilizado um analisador de gases por infravermelhos - IRGA (LC pro+, Analytical Development Company, Hoddesdon, Reino Unido). Durante as avaliações, a umidade relativa do ar foi de $\approx 80 \pm 5 \%$, a temperatura foliar variou de 28 a $32{ }^{\circ} \mathrm{C}$, a concentração ambiente de $\mathrm{CO}_{2}$ foi cerca de 380 $\mu \mathrm{mol} \mathrm{mol}{ }^{-1} \mathrm{e}$ irradiância de saturação de 1000 $\mu \mathrm{mol}$ de fótons $\mathrm{m}^{-2} \mathrm{~s}^{-1}$. Foram tomados os parâmetros: taxa de assimilação líquida de carbono $\left(A-\mu \mathrm{mol} \mathrm{CO}_{2} \mathrm{~m}^{-2} \mathrm{~s}^{-1}\right)$; condutância estomática ao vapor de água $\left(g_{s}-\mathrm{mmol} \mathrm{H}_{2} \mathrm{O} \mathrm{m}{ }^{-2}\right.$ $\left.\mathrm{s}^{-1}\right)$; taxa transpiratória $\left(E-\mathrm{mmol} \mathrm{H}_{2} \mathrm{O} \mathrm{m}{ }^{-2} \mathrm{~s}^{-1}\right)$; eficiência instantânea no uso da água $(A / E$ ( $\mu \mathrm{mol}$ de $\mathrm{CO}_{2} \mathrm{mmol}^{-1}$ de $\mathrm{H}_{2} \mathrm{O}$ ) e relação entre as concentrações interna e externa de carbono $\left(C_{i}\right.$ $\left./ C_{a}\right)$.

Os resultados obtidos foram submetidos à análise de variância utilizando-se o programa estatístico SAEG (RIBEIRO JÚNIOR, 2001), sendo os tratamentos comparados pelo teste de Tukey a 5\% de probabilidade

\section{Resultados e Discussão}

Houve efeito significativo das telas de sombreamento sobre todas as variáveis da produção de alface (Tabela 1). A altura das plantas e o diâmetro da cabeça apresentaram aumentos de 20,90 e $59,54 \%$, respectivamente, quando comparado o plástico transparente de $150 \mu \mathrm{m}$ ao 
pleno sol (Tabela 1). Estes resultados estão de acordo com aqueles obtidos por Bezerra Neto et al. (2005a), os quais observaram que a tela transparente proporcionou incrementos em altura e diâmetro da cabeça das plantas de alface em relação ao pleno sol. Também, Queiroga et al. (2001) verificaram que as cultivares de alface Verônica e Regina apresentaram incrementos em altura quando cultivadas sob tela branca em relação à preta, e por outro lado as telas não influenciaram o diâmetro das plantas. Sentelhas;
Villa Nova; Angelocci (1998) asseguram que as telas brancas provocam menor irradiação solar global $(26,6 \%)$ e menor luminosidade $(25,1 \%)$ em relação à tela preta, com irradiação solar global de $55,4 \%$ e luminosidade de $52,3 \%$, e os incrementos sobre a altura e diâmetro das plantas aqui obtidos sob esta tela podem ser atribuídos à maior taxa fotossintética e produção de fotossintatos e menor transpiração das plantas (Tabela 2) alcançados através da redução dos efeitos extremos da radiação.

Tabela 1 Altura de planta (APL), diâmetro da cabeça (DCB), número de folhas por planta (NFP), massa fresca de uma planta (MFP), matéria seca total (MST), razão de massa de caule (RMC), de folha (RMF) e produtividade (PRO) de alface crespa cultivar Elba cultivada sob diferentes telas de sombreamento, plástico transparente e pleno sol em Santarém-PA

\begin{tabular}{|c|c|c|c|c|c|}
\hline \multirow[b]{2}{*}{ Variáveis } & \multicolumn{5}{|c|}{ Ambientes } \\
\hline & Pleno sol & $\begin{array}{c}\text { Tela preta } \\
50 \%\end{array}$ & $\begin{array}{c}\text { Tela verde } \\
50 \%\end{array}$ & $\begin{array}{l}\text { Plástico } \\
150 \mu \mathrm{m} \\
\end{array}$ & $\mathrm{CV}(\%)$ \\
\hline Altura $(\mathrm{cm})^{* *}$ & $14,95 \mathrm{c}$ & $15,71 b$ & $15,50 b$ & $18,90 \mathrm{a}$ & 3,36 \\
\hline Diâmetro $(\mathrm{cm})^{* *}$ & $19,08 \mathrm{c}$ & $27,08 \mathrm{~b}$ & $28,30 \mathrm{~b}$ & $30,44 \mathrm{a}$ & 3,67 \\
\hline Número de folhas ${ }^{* *}$ & $17,50 \mathrm{c}$ & $23,50 b$ & $32,85 \mathrm{a}$ & $29,92 \mathrm{a}$ & 5,44 \\
\hline Massa fresca de uma planta $(\mathrm{g})^{*}$ & $195,04 \mathrm{c}$ & $302,40 \mathrm{~b}$ & $384,46 a$ & $378,56 a$ & 6,65 \\
\hline Massa seca $\left(\mathrm{t} \mathrm{ha}^{-1}\right)^{* *}$ & $2,84 \mathrm{~b}$ & $4,15 b$ & $4,73 a$ & 4,61a & 3,90 \\
\hline $\operatorname{RMF}(\%)^{\mathrm{ns}}$ & $86,99 \mathrm{a}$ & $83,52 \mathrm{a}$ & $86,97 \mathrm{a}$ & $86,37 \mathrm{a}$ & 2,99 \\
\hline $\operatorname{RMC}(\%)^{* *}$ & $13,01 b$ & $16,48 \mathrm{a}$ & $13,03 b$ & $13,63 b$ & 16,53 \\
\hline Produtividade $\left(\mathrm{t} \mathrm{ha}^{-1}\right)^{* *}$ & $31,21 \mathrm{c}$ & $48,38 b$ & $61,51 \mathrm{a}$ & $60,57 \mathrm{a}$ & 6,50 \\
\hline Incremento de produtividade sobre testemunha (\%) & - & 35,49 & 49,26 & 48,47 & - \\
\hline
\end{tabular}

Médias na linha seguidas pela mesma letra não diferem entre si pelo teste de Tukey a $5 \%$ de probabilidade. CV: coeficiente de variação. ${ }^{\text {ns, }}$ ** ou *: não significativo, significativo a $1 \%$ ou $5 \%$ de probabilidade pelo teste $F$, respectivamente.

Tabela 2 Taxa assimilatória líquida de carbono $(A)$, transpiração $(E)$, condutância estomática $\left(g_{s}\right)$, eficiência instantânea no uso da água $(A / E)$ e relação entre as concentrações interna e externa de carbono $\left(C_{i} / C_{a}\right)$ de alface crespa cultivar Elba cultivada sob diferentes telas de sombreamento em Santarém-PA

\begin{tabular}{lccccc}
\hline \multirow{2}{*}{ Variáveis } & \multicolumn{5}{c}{ Ambientes } \\
\cline { 2 - 6 } & \multirow{2}{*}{ Pleno sol } & $\begin{array}{c}\text { Tela preta } \\
50 \%\end{array}$ & $\begin{array}{c}\text { Tela verde } \\
50 \%\end{array}$ & $\begin{array}{c}\text { Plástico } \\
150 \mu \mathrm{m}\end{array}$ & $\mathrm{CV}(\%)$ \\
\hline$A\left(\mu \mathrm{mol} \mathrm{CO} \mathrm{C}^{-2} \mathrm{~s}^{-1}\right)^{* *}$ & $13,24 \mathrm{c}$ & $15,78 \mathrm{~b}$ & $15,65 \mathrm{~b}$ & $17,44 \mathrm{a}$ & 8,00 \\
$E\left(\mathrm{mmol} \mathrm{H}_{2} \mathrm{O} \mathrm{m}^{-2} \mathrm{~s}^{-1}\right)^{*}$ & $4,70 \mathrm{~b}$ & $4,97 \mathrm{a}$ & $5,16 \mathrm{a}$ & $4,85 \mathrm{a}$ & 6,37 \\
$g_{s}\left(\mathrm{mmol} \mathrm{H}_{2} \mathrm{O} \mathrm{m}^{-2} \mathrm{~s}^{-1}\right)^{* *}$ & $920,63 \mathrm{~d}$ & $1096,25 \mathrm{~b}$ & $1127,50 \mathrm{a}$ & $1023,75 \mathrm{c}$ & 10,23 \\
$A / E\left(\mu \mathrm{mol} \mathrm{CO} \mathrm{mmol} \mathrm{H}_{2} \mathrm{O}^{-1}\right)^{* *}$ & $2,81 \mathrm{c}$ & $3,18 \mathrm{~b}$ & $3,03 \mathrm{~b}$ & $3,60 \mathrm{a}$ & 8,87 \\
$C_{i} / C_{a}^{* *}$ & $0,83 \mathrm{a}$ & $0,81 \mathrm{~b}$ & $0,81 \mathrm{~b}$ & $0,78 \mathrm{c}$ & 4,30 \\
\hline
\end{tabular}

Médias na linha seguidas pela mesma letra não diferem entre si pelo teste de Tukey a 5\% de probabilidade. CV: coeficiente de variação. ${ }^{\text {ns }}$, ** ou *: não significativo, significativo a $1 \%$ ou $5 \%$ de probabilidade pelo teste $F$, respectivamente.

O número de folhas foi estatisticamente igual para as telas de sombreamento verde e o plástico, e superiores em relação ao pleno sol, com incrementos de $46,72 \%$ (verde) e $41,51 \%$ (plástico) (Tabela 1). A exposição direta à radiação solar provocou a formação de folhas alongadas e estreitas, ao contrário do que aconteceu às plantas sombreadas, que produziram folhas com formato oval, ou seja, curta e larga do ápice para a base. Nossos resultados se assemelham a aqueles obtidos por Queiroga et al. (2001), que não constataram diferenças entre a tela verde e o plástico sobre o número de folhas da alface. Por outro lado, Bezerra Neto et al. (2005a) observaram que a tela verde apresentou desempenho superior ao pleno sol em relação ao 
número de folhas e à produtividade da alface. Bezerra Neto et al. (2005b) relataram que as mudas de alface produzidas sob tela de sombreamento, mesmo sendo menores que as produzidas a céu aberto, apresentam folhas em maior número, o que favorece melhor desempenho fisiológico. Ainda de acordo com esses autores, o excesso de radiação e temperatura alta podem levar a muda a um estado de estresse fisiológico, impedindo o seu desenvolvimento normal.

Maior acúmulo de massa fresca e maiores produtividades foram observados nas alfaces cultivadas sob tela verde e no plástico. Em relação à massa fresca, foram obtidos incrementos de $49,27 \%$ sob tela verde e $48,42 \%$ sob o plástico. Quanto à produtividade, foram constatados ganhos de 49,26\% para a tela verde, e de $48,47 \%$ para o plástico, ao compará-las ao cultivo sob pleno sol (Tabela 1). Em alfaces cultivadas nas condições edafoclimáticas do Rio Grande do Norte, aumentos de $27 \%$ na produtividade foram proporcionados pelo uso de sombreamento com tela branca, quando comparado ao cultivo sem sombreamento (QUEIROGA et al., 2001; BEZERRA NETO et al., 2005a). Entretanto, Costa et al. (2011a) observaram que o sombreamento promoveu aumentos na produção total e na massa fresca dos frutos, os quais foram atribuídos à radiação fotossinteticamente ativa, colaborando para a obtenção de temperatura constante no interior do ambiente, favorecendo a concentração do florescimento, além de proporcionar maiores taxas fotossintéticas. Em estudos com rúcula em Cáceres-MT, Costa et al. (2011b) constataram que a produção em campo aberto apresentou valores aceitáveis, mostrandose viável, porém sob tela preta de $50 \%$, houve incremento na produção em cerca de $43 \%$ e antecipação da colheita. Semelhantemente, Santana et al. (2009) observaram que a tela de sombreamento preto $50 \%$ proporcionou maior acúmulo de massa fresca em alface roxo.

Neste estudo, pode-se afirmar que os incrementos em produtividade são devidos ao maior número de folhas fotossinteticamente ativas, favorecendo o acúmulo individual de massa fresca, resultado da alteração dos comprimentos de onda e da temepratura sob a tela verde e o plástico.

Os tratamentos telas de sombreamento verde e o plástico não diferiram estatisticamente entre si quanto à massa seca, mas foram estatisticamente superiores ao tratamento pleno sol, com incrementos de 39,95\% (verde) e 38,4\% (plástico) (Tabela 1). Na tela preta de 50\%, observou-se incremento na RMC de 21,05\% em relação ao pleno sol, enquanto que a RMF não diferiu estatisticamente entre as telas e o plástico adotados (Tabela 1). Os aumentos da massa seca observados na tela verde e no plástico transparente de $150 \mu \mathrm{m}$ ocorreram devido ao maior número de folhas e maior alocação de biomassa nestas em relação ao caule, sendo um indicativo de que os tipos de sombreamento adotados não ocasionaram estiolamento das plantas e não interferiram no desenvolvimento. Aquino et al. (2007) observaram maior produção de massa seca da parte aérea em alfaces conduzidos a pleno sol em relação às telas termorefletoras e termoprotetoras. Esses autores atribuíram esse fato à redução na incidência de radiação sob as telas. Kleemann (2004) obteve plantas de alface cultivadas sob cobertura de plásticos fotoseletivo com melhor aspecto e qualidade do que aquelas cultivadas a céu aberto, apesar de seus rendimentos e qualidade não diferirem significativamente entre.

Os tratamentos adotados neste trabalho influenciaram significativamente $(\mathrm{p}<0,01)$ todos os parâmetros fisiológicos das plantas de alface. A taxa fotossintética $(A)$ e a eficiência no uso da água $(A / E)$ foram influenciadas pelo sombreamento, ocorrendo aumentos de $24,1 \%$ e $21,94 \%$, respectivamente, com o uso do plástico em relação à condução em pleno sol (Tabela 2). Edmond; Senn; Andrews (1967) observaram que numa cultura, quando conduzida dentro de variação ótima de luminosidade com outros fatores favoráveis, a fotossíntese é elevada e a quantidade de carboidratos utilizados para o crescimento e desenvolvimento da planta é alta. Em estudos realizados em couve chinesa (Brassica oleracea) (ISSARAKRAISILA; MA; TURNER, 2007) e orégano (Origanum vulgare L.) (MARQUES; BERNARDI FILHO; SANTOS, 2009), foi constatada correlação positiva entre a fotossíntese e a transpiração em plantas desenvolvidas em ambiente protegidos. Outros estudos verificaram que em diferentes espécies cultivadas em ambiente protegido, com concentração de $\mathrm{CO}_{2}$ elevada, ocorreu aumento instantâneo da eficiência do uso da água, relacionado com a diminuição da condutância e transpiração (CANIZARES; RODRIGUES; 
GOTO, 2004; ERISMANN; MACHADO; GODOY, 2006). No presente estudo podemos afirmar que a maior eficiência no uso da água sob o plástico deve-se essencialmente a maior condutância estomática e maior influxo de $\mathrm{CO}_{2}$, resultando em maior taxa fotossintética. Uma vez que ocorreu maior transpiração, os incrementos em $A / E$ foram resultantes dos acréscimos obtidos com sustentados principalmente pelos incrementos em $A$.

A condutância estomática $\left(g_{s}\right)$ e a transpiração $(E)$ das plantas conduzidas sob tela verde apresentaram aumentos de 18,35\% e $8,91 \%$, respectivamente, em relação àquelas em pleno sol (Tabela 2). O uso de telas de sombreamento em locais de temperatura e luminosidade elevadas pode contribuir para diminuir os efeitos extremos da radiação, principalmente a fotorrespiração, e proporcionar maior produtividade e qualidade das folhas para consumo (SILVA, 1998). No estudo aqui analisado foi verificada maior abertura estomática e ao mesmo tempo maior influxo de carbono, resultando em ganho na taxa fotossintética, porém com um ônus de maior transpiração às plantas (Tabela 2). Esses dados corroboram com os obtidos por Santos et al. (2010), os quais verificaram que os aumentos da $g_{s}$ levou ao aumento do $C_{i}$, aumentando, consequentemente, a fotossíntese.

A relação entre o carbono interno e externo $\left(C_{i} / C_{a}\right)$ foram influenciadas pelo sombreamento, ocorrendo redução de $6,42 \%$ com o uso do plástico em relação ao tratamento pleno sol (Tabela 2). Alterações na taxa fotossintética podem ser ocasionadas por limitações estomáticas com mudanças na abertura dos estômatos e resistência ao influxo de $\mathrm{CO}_{2}$, ou limitações nas reações bioquímicas e inibição da atividade da Rubisco, desse modo, através da relação $C_{i} / C_{a}$ pode-se constatar a eficiência ou ineficiência nas reações de fixação de carbono, sendo que quanto mais se aproximar de 1 essa razão, menos eficiente esse processo, em razão de problemas na maquinaria fotossintética. As telas de sombreamento reduzem os efeitos nocivos da incidência da altas taxas de radiação solar e da temperatura sobre a planta. Assim, podemos afirmar que as reduções em $C_{i} / C_{a}$ observadas sob as diferentes telas devem-se à minimização dos efeitos da radiação excessiva sobre as plantas de alface e a uma maior eficiência das reações de fixação de $\mathrm{CO}_{2}$, finalizando com a maior taxa fotossintética e por consequência, maior acúmulo de massa seca.

Podemos afirmar que as maiores produção de massa seca e RMF aqui obtidas se devem à maior disponibilidade e captação de luz em função do maior número de folhas sob o sombreamento, além do microclima favorecendo maior influxo de $\mathrm{CO}_{2}$ e menor transpiração das plantas com melhor eficiência no uso da água, além da maior disponibilidade e captação de luz na faixa fotossinteticamente ativa.

Os incrementos observados nos componentes de produtividade e nos parâmetros de trocas gasosas no plástico se devem ao maior fluxo de fótons no ambiente, consequentemente maior condutância estomática, influxo de $\mathrm{CO}_{2}$, fotossíntese e por fim, produção de biomassa.

Contrariamente, Miceli e D’Anna (2003) observaram que o uso de diversos filmes plásticos de longa duração no cultivo de hortaliças, em túneis, influenciaram apenas a produtividade de algumas espécies. Todavia, em neste estudo, pode-se afirmar que a tela de sombreamento verde e o plástico transparente proporcionaram alterações positivas na atividade fotossintética as quais se constituíram nas principais responsáveis pelo aumento na produtividade da alface.

\section{Conclusão}

As maiores produtividades obtidas na tela verde e no plástico foram resultado do maior número de folhas, maior peso de uma planta e maior alocação de massa seca para as folhas;

As telas de sombreamento aumentaram a produtividade da alface através de incrementos na sua atividade fotossintética. No cultivo sob plástico ocorreram a maior condutância estomática e concentração de $\mathrm{CO}_{2}$, que por sua vez proporcionaram incrementos na taxa fotossintética, melhor eficiência instantânea no uso da água $(A / E)$, fixação de $\mathrm{CO}_{2}\left(C_{i} / C_{a}\right)$ e o maior acúmulo de massa seca.

\section{Agradecimento}

Ao CNPq pela concessão da bolsa IC ao segundo autor; à Canto Verde Hortaliças pela área para condução do experimento.

\section{Referências}

ANTUNES, O. T. et al. Produção de cultivares de morangueiro polinizadas pela abelha jataí em 
ambiente protegido. Horticultura Brasileira, v. 25 , n. 1 , p. $60-65,2007$.

AQUINO, L. A. et al. Produção de biomassa, acúmulo de nitrato, teores e exportação de macronutrientes da alface sob sombreamento. Horticultura Brasileira, v. 25, n. 3, p. 381386, 2007.

BEZERRA NETO, F. et al. Produtividade de alface em função de condições de sombreamento e temperatura e luminosidade elevadas. Horticultura Brasileira, v. 23, n. 2, p. 189-192, 2005a.

BEZERRA NETO, F. et al. Sombreamento para produção de mudas de alface em alta temperatura e ampla luminosidade. Horticultura Brasileira, v. 23, n. 1, p. 133137, 2005b.

CANIZARES, K. A. L.; RODRIGUES, J. D.; GOTO, R. Crescimento e índices de troca gasosa em plantas de pepino irrigadas com água enriquecida com $\mathrm{CO}_{2}$. Horticultura Brasileira, v. 4, n. 22, p. 706-711, 2004.

COSTA, C. M. F. et al. Desempenho de cultivares de rúcula sob telas de sombreamento e campo aberto. Semina: Ciências Agrárias, v. 32, n. 1, p. 93-102, 2011b.

COSTA, R. C. et al. Telas de sombreamento na produção de morangueiro em ambiente protegido. Horticultura Brasileira, v. 1, n. 29, p. $98-102,2011$ a.

EDMOND, J. B.; SENN, T. L.; ANDREWS, E. S. Princípios de horticultura. México: Continental, 1967. p. 119-134.

ERISMANN, N. M.; MACHADO, E. C.; GODOY, I. J. Capacidade fotossintética de genótipos de amendoim em ambiente natural e controlado. Pesquisa Agropecuária Brasileira, v. 41, n. 7, p. 1099-1108, 2006.

HE, J.; TAN, L. P.; LEE, S. K. Root-zone temperature effects on photosynthesis, 14Cphotoassimilate partitioning and growth of temperate lettuce (Lactuca sativa cv. 'Panama') in the tropics. Photosynthetica, v. 47, n. 1, p. 95-103, 2009.

HUERTAS, L. Control ambiental em el vivero. Horticultura Internacional, n. extra, p. 7784, 2006.

ISSARAKRAISILA, M.; MA, Q.; TURNER, D.
W. Photosynthetic and growth responses of juvenile Chinese kale (Brassica oleracea var. alboglabra) and Caisin (Brassica rapa subsp. parachinensis) to waterlogging and water deficit. Scientia Horticulturae, v. 111, p. 107113, 2007.

KIM H. H. et al. Stomatal conductance of lettuce grown under or exposed to different light qualities. Annals of Botany, v. 94, p. 691-697, 2004.

KLEEMANN, M. Effect of photoselective plastics on the quality of lettuce. Acta Horticulturae, v. 633, n. 1, p. 173-179, 2004.

LI, J. C. Uso de mallas en invernaderos. Horticultura Internacional, n. extra, p. 8691, 2006.

MARQUES, P. A. A.; BERNARDI FILHO, L.; SANTOS, A. C. P. Crescimento, produção de óleo essencial e trocas gasosas em orégano influenciados por diferentes lâminas de irrigação. Ciência Rural, v. 39, n. 6, p. 18881892, 2009.

MICELI, A.; D'ANNA, F. Effect of different plastic cover films on the production of some vegetable crops. Acta Horticulturae, v. 614, p. 421-42, 2003.

PEREIRA, F. H. F. et al. Growth, assimilate partition and yield of melon charenthais under different shading screens. Horticultura Brasileira, v. 29, n. 1, p. 91-97, 2011.

QUEIROGA, R. C. F. et al. Produção de alface em função de cultivares e tipos de tela de sombreamento nas condições de Mossoró. Horticultura Brasileira, v. 19, n. 3, p. 324328, 2001.

RIBEIRO JÚNIOR, I. R. Análises estatísticas no SAEG. Viçosa: UFV. 301 p. 2001.

RIBEIRO, A. C.; GUIMARÃES, P. T. G.; ALVAREZ, V. H. Recomendações para o uso de corretivos e fertilizantes em Minas Gerais: $\mathbf{5}^{\mathbf{a}}$ aproximação. Viçosa: Comissão de fertilidade do solo do estado de Minas Gerais. 359 p. 1999.

SANTANA, C. V. S. et al. Produção de alface roxa em ambientes sombreados na região do submédio São Francisco-BA. Revista Verde, v. 4, n. 3, p. 01-06, 2009. 
SANTOS, C. M.. Atividade fotossintética em alface (Lactuca sativa L.) submetidas a diferentes compostagens de resíduos agroindustriais. Pesquisa Aplicada \& Agrotecnologia, v. 3, n. 3, p. 103-112, 2010.

SENTELHAS, P. C.; VILLA NOVA, N. A.; ANGELOCCI, L. R. Efeito de diferentes tipos de cobertura, em mini-estufas, na atenuação da radiação solar e da luminosidade. Revista Brasileirade Agrometeorologia, v. 6, n. 1, p.479-481, 1998.

SHAHAK, Y. et al. Greenblat-AvronColorNets: a new approach for light manipulation in fruit trees. Acta Horticulturae, v. 636, p. 609-616, 2004.
SILVA, A. R.; NECHET, D. 2006. Características Climáticas de Alguns Municípios Produtores de Soja do estado do Pará. In: CONGRESSO BRASILEIRO DE METEOROLOGIA, 14. Anais...Florianóplois - SC. Disponível em: http://www.cbmet.com/edicoes.php?pageNu $\mathrm{m}$ _Recordset_busca $=4 \&$ totalRows_Recordse t_busca $=1006 \&$ cgid $=14$. Acesso em: 10 de Setembro de 2012.

SILVA, V. F. Cultivares de alface em diferentes espaçamentos sob temperatura $\mathrm{e}$ luminosidade elevadas. 1998. $25 \mathrm{f}$. Dissertação (Mestrado em Agronomia/Fitotecnia) - Universidade Federal Rural do Semi-Árido, Mossoró, 1998. 